\title{
Socio-Ecopreuneur Untuk Mensejahterakan Pengrajin Bambu Di Desa Hargomulyo, Gedangsari, Gunung Kidul, Yogyakarta Dalam Momentum Masyarakat Ekonomi Asean( Mea)
}

\author{
Robist Hidayat ${ }^{* 1}$, M. Irfan Zidni*2 \\ ${ }^{1,2}$ Universitas Muhammadiyah Yogyakarta \\ e-mail: robisth96@gmail.com
}

\begin{abstract}
Informasi Artikel
Diterima Redaksi: 16 Januari 2019

Revisi Akhir: -

Diterbitkan Online: 4 Februari 2019

Kata Kunci

AEC, Bambu, industry kreatif,

Masyarakat, Teknologi
\end{abstract}

Korespondensi :

No. HP: -

\begin{abstract}
What happened in Indonesia, bamboo continued to be cut down without any effort to plant and maintain so that the number of bamboo populations continued to decline. Some areas with good potential for bamboo include Gunungkidul, Special Region of Yogyakarta. Efforts to increase the value of bamboo also need to be balanced with conservation efforts as an increase in bamboo biodiversity itself. The existence of the Asean Economic Community (AEC) at the end of 2015 is a broader economic and market integration. This indicates open competition for trade in goods, services, investment, capital and workers. From these problems, we create a socio-ecopreneur with the theme "a million bamboos for my Indonesia". This product is made from $100 \%$ bamboo material, then innovates on bamboo crafts to become a creative, eco-friendly, sustainable, and originally hand made industrial product. This product is suitable for use as house accessories, household utilities, and others. This product uses traditional lamination technology (press) and bamboo preservation. we also developed a bamboo business management model that is beneficial for the economic resilience of local communities, especially for communities in Hargomulyo Village and at the same time beneficial to environmental biodiversity. Using a global interconnection ethnographic approach where we and the community are fully involved in the activity process starting from assessment, planing, implementation (action), until monitoring-evaluation.
\end{abstract}

\section{PENDAHULUAN}

Bambu bukan menjadi komoditas yang asing pada masyarakat Indonesia. Bahkan secara historis sebelum semen, besi, dan plastik masuk ke pelosokpelosok tanah air, masyarakat kita sangat akrab dengan bambu. Mereka memanfaatkan bambu untuk berbagai keperluan, seperti bahan bangunan, wadah, anyaman, dan sebagainya. Barangkali karena beragam manfaat itulah akhirnya bambu mendapat posisi penting dalam kehidupan masyarakat di pedesaan di samping kayu. Berdasarkan laporan Pusat Studi Asia Pasifik Universitas Gadjah Mada. Dari sekitar 1.250 jenis bambu yang sudah dikenal di dunia, 11\%-nya merupakan jenis asli Indonesia. Jumlah dan jenis bambu terbanyak terdapat di Sumatera (56 jenis) dan Jawa (60 jenis). Secara ekologis bambu sangat menguntungkan bagi lingkungan karena menghasilkan biomassa tujuh kali lipat dibanding hutan pepohonan serta berperan dalam mencegah erosi karena dapat memperkuat ikatan partikel tanah dan menahan limpasan air. Selain itu, rumpun bambu mampu menyerap karbon dalam jumlah besar sehingga sangat strategis dalam mengurangi atau mencegah global warming. Tidak heran jika perusahaanperusahaan besar dunia banyak yang melirik bambu untuk menyerap karbon 
yang telah mereka keluarkan sebagai bentuk pertanggungjawaban terhadap lingkungan. Keunggulan bambu yang lain adalah sifatnya yang dapat diperbaharui dan banyak tersedia di Indonesia. Jika menelisik dengan seksama kebiasaan para orang tua di pedasaan, mereka sesungguhnya memiliki kearifan dalam pemanenan agar mendapat bambu yang berkualitas dan awet. Dengan begitu, berarti mereka sudah mengenal pengelolaan rumpun yang baik. Penebangan bambu yang tua memang mutlak dilakukan untuk menjaga nutrisi tanah dan kualitas bambu di rumpun tetap baik. Jika panen kayu harus menunggu 2040 tahun, maka bambu bisa dipanen setiap tahun. Bambu memang harus dipanen, karena jika tidak, rumpun bambu menjadi tidak sehat. Ini adalah prinsip keseimbangan alam yang luar biasa karena ketika kita memanen dan memanfaatkan bambu dengan benar, berarti kita turut dalam menjaga lingkungan. Di sinilah letak strategis bambu untuk mengganti kayu yang kian langka dan hutan yang terus rusak. Mengelola dan memanfaatkan bambu berarti kita membantu menyelamatkan kerusakan hutan di Indonesia (INBAR, 2001). Bambu memiliki nilai ekonomis yang tidak diragukan lagi. Bambu merupakan sumber makanan (shoots), dan karena memilki atribut-atribut yang membuat produk turunan memiliki nilai ekonomis yang amat tinggi. Beberapa atribut antara lain adalah :kelenturan (flexibility, strength, dan hardiness, tahan berbagai hama, air, dan mengandung cellulose yang tinggi). Dengan demikiakan serangkaian produk dari bambu antara lain adalah: bahan mentah untuk membuat furniture, berbagai handicracft, bahan konstruksi, bahan pembuatan kertas yang bernilai tinggi, dan sebagai bahan bakar. Nilai ekonomis bambu yang tidak langsung, adalah bambu sebagai tanaman yang memiliki daya penyerapan $\mathrm{CO} 2$ yang tinggi, sehingga digunakan dibanyak tempat untuk mengurangi pemanasan global-tanaman bagus dalam upaya carbon sequestration. (Jansen, Jules, 2007). Agar geliat masyarakat dalam menjalankan usaha bambu terus meningkat, maka perlu membuka pasar bambu secara lebih luas di skala nasional dan international. Saat ini, bambu di Indonesia sudah mulai diekspor ke berbagai negara. Berbicara mengenai pemasaran bambu ke dunia international tidak lepas pula membicarakan mengenai membuka sekat antara yang lokal dan yang global.Adanya AEC pada akhir tahun 2015 harus bisa dimanfaatkan dengan baik. Hal ini merupakan peluang terbukanya sekat perekonomian antar bangsa. Dengan adanya AEC, semua faktor produksi yang ada di kawasan Asia Tenggara bisa bergerak melewati batas negara dan penghalang (sekat) perekonomian anatar negara di Asia Tenggara. Kebanyakan masyarakat Indonesia belum begitu menangkap apa itu AEC dan dampak yang akan dirasakan. Untuk itu, perlu pendampingan secara dini serta pemberdayaan masyarakat yang potensial dengan produk yang dijual di pasar.

Seperti produk bambu yang memiliki nilai ekologi, sosial, bahkan ekonomi, perlu dioptimalkan pemanfaatannyadan dikembangkan produk turunan bambu. Dengan demikian akan mendukung terciptanya One Village One Product (spesialisasi produk untuk satu wilayah) sehingga pemasaran kawasan beserta produk potensialnya bisa difokuskan. Hal ini secara tidak langsung akan mendukung program pemerintah yaitu OVOP (One Village One Product) dan juga bisa meningkatkan kesejahteraan masyarakat setempat. Berangkat dari fenomena di atas, kami merasa tertarik untuk melakukan usaha sekaligus program pengabdian masyarakat berupa kerajinan bambu yang.. Kami merasa sebuah usaha harus memiliki nilai keberlajutan yang baik secara sosial-ekonomi maupun lingkungan. Adapun tempat pelaksanaannya, berada di Desa Hargomulyo, Kecamatan Gedangsari, Kabupaten Gunungkidul. Mengapa harus Hargomulyo, karena desa ini dikenal sebagai sentral pengrajin bambu. Namun fakta membuktikan mata pencaharian dominan masyarakat lokal bukan pengrajin bambu akan tetapi petani. Dengan demikian kami membentuk usaha 
kerajinan bambu yang inovatif dengan tema "sejuta bambu untuk indonesiaku" sebagai socio-ecopreneur.

Bambu di Indonesia belum mendapat tempat yang layak karena dianggap sebagai bahan milik orang miskin dan dianggap sebagai rumput yang tidak perlu dipelihara. Akibatnya banyak komunitas tanaman bambu yang dikonversi untuk pemukiman dan ladang. Beberapa daerah yang menyisakan populasi bambu yang relatif banyak dan masih sehat adalah Desa Hargomulyo, Kecamatan Gedangsari, Daerah Istimewa Yogyakarta. Oleh sebab itu, perlu upaya penyelamatan serta pengembangan usaha socioecopreneur inovasi bambu agar dapat meningkatkan penghidupan masyarakat. Sehingga dapat bersaing dalam komunitas Masyarakat Ekonomi ASEAN/Asean Economic Community (AEC).

\section{METODE}

Tahap perencanaan dan desain dimulai dengan melakukan perancangan dan pengembangan produk berdasarkan consumer need. Masukan dari pasar potensial diolah dan diterjemahkan menjadi konsep produk jadi. Dalam pengembangan produk juga mengacu pada prinsip (DFM) Design for Manufacturing, sehingga desain tersebut dapat direalisasikan.

\subsection{Persiapan dan Pelaksanaan Produksi}

Setelah menerima desain layak dipasarkan departemen produksi melakukan perencanaan yakni : Rencana sistem produksi dan lay-out kerja yang paling cocok dengan kondis lapangan., Pemelihan supplier dan mitra kerja sama yaitu masyarakat. Dan pengadaan barang baku produksi dan peralatan penunjang produksi masal. Tahapan setelah perancanaan produksi ialah produksi masal sesuai analisis permintaan berdasarkan minat dan antusias pasar. Untuk menjaga kualitas, proses quality control dilakukan dengan sistem auton omasi yaitu sistem pengecekan bertingkat pada setiap prosesnya.

\subsection{Publikasi dan Pemasaran}

Pada tahap publikasi dan pemasaran langkah yang ditempuh yaitu sebagai berikut:

a. Strategi Fokus, yaitu membentuk hierarki kelompok pasar potensial dan membidik pasar yang paling berpotensi pertama kali.

b. Strategi Off-line, yaitu pemasaran dengan cara penjualan langsung, pembukaan stand pada acara lokal, nasional, maupun international sehingga merupakan langkah awal untuk merintis jaringan pasar ke seluruh Indonesia. Selain itu, langkah penempatan distributor dibeberapa tempat strategis.

c. Strategi On-line, yaitu dengan cara pembuatan web-site, akun jejaring sosial sebagai sarana komunikasi jarak jauh dengan menyediakan detail produk.

\section{HASIL DAN PEMBAHASAN}

Evaluasi dan keberlanjutan dilakukan dengan cara mengolah feedback dari pasar, serta melakukan pengembangan keberlanjutan untuk pengembangan usaha selanjutnya. Evaluasi ini akan dilakukan setiap bulan sekali menggunakan metode Plan-Do-Check. Setiap strategi memiliki fokus evaluasinya masingmasing disamping evaluasi secara keseluruhan, yaitu:

a. Evaluasi strategi produksi, terus meningkatkan sistim produksi yang efektif baik dari sisi pekerja maupun proses pembuatan untuk memenuhi kebutuhan pasar.

b. Evaluasi strategi pemasaran, membuat inovasi guna meningkatkan jangkauan pasar dan meningkatkan profit usaha kerajinan bambu.

c. Evaluasi strategi publikasi, mengupdate semua follow-up kegiatan sehingga dapat berdampak secara tidak langsung terhadap penjualan 
dan jangkauan penjualan.

d. Evaluasi strategi desain, melihat peluang inovasi baru yang dapat diterapkan.

\section{KESIMPULAN}

Kesimpulan harus mengindikasi secara jelas hasil-hasil yang diperoleh, kelebihan dan kekurangannya, serta kemungkinan pengembangan selanjutnya. Adapun kesimpulan dari hasil kegiatan pengabdian ini adalah sebagai berikut:

a. Tenaga kerja yang digunakan yaitu masyarakat asli Desa Hargomulyo, Kecamatan Gedangsari, Kabupaten Gunungkidul dan sekitarnya. Sehingga tanpa di sadari sudah membuka peluang kerja bagi masyarakat disana. Mereka tidak hanya mengandalkan pertanian sebagai mata pencaharian utama bagi mereka melainkan mempunyai sampingan kerajinan bambu sebagai penopang hidup. Memberikan wadah untuk pemuda serta anak-anak setempat berkarya dan berinovasi membentuk ragam bentuk agar produk tersebut bisa berkelas dan banyak diminati

b. Ini adalah hal yang positif yang bisa kita berikan kepada daerah dan negara selain membantu mengurangi pengganguran, kita bisa memgembangkan UMKM yang mempunyai pangsa pasar yang sangat luas terutama hal ekonomi kreatif rakyat yang menjadi tolak ukur untuk memulai persaingan di Asean Economics community sehingga kita sebagai bangsa yang besar bisa bersaing dengan negara lain dalam hal industry kreatif. Selain itu menjadi salah satu destinasi baru untuk wisatawan lokal maupun mancanegara, sehingga menjadi salah satu pendapatan daerah setempat melaui desa wisata kerajinan bambu di wilayah Gunung Kidult

c. Bisa menjadi pioner usahawan muda dikalah minimnya mahasiswa dan pemuda berkontribusi untuk masyarakat dimana sudah muncul era Young, yang muda yang berkontribusi masyarakat dan membantu gerakan pemerintah mengurangi angka kemiskinan di negara kita. Serta bisa terjun langsung ke masyarakat agar skills besosialisasinya terbentuk dan menjadi mental yang kuat tidak lemah menghadapi lingkungan yang sesunggunhnya. Sebagai wadah menuangkan kreatifitas dan juga belajar menjadi Young Entrepeuner.

\section{SARAN}

Adapun saran dari kegiatan pengabdian ini untuk lebih optimal lagi dalam membantu meningkatkan kapasitas usaha rumah tangga keripik dan kue bawang yaitu:

a. Evaluasi strategi produksi, terus meningkatkan sistim produksi yang efektif baik dari sisi pekerja maupun proses pembuatan untuk memenuhi kebutuhan pasar.

b. Evaluasi strategi pemasaran, membuat inovasi guna meningkatkan jangkauan pasar dan meningkatkan profit usaha kerajinan bambu.

c. Evaluasi strategi publikasi, mengupdate semua follow-up kegiatan sehingga dapat berdampak secara tidak langsung terhadap penjualan dan jangkauan penjualan.

d. Evaluasi strategi desain, melihat peluang inovasi baru yang dapat diterapkan.

\section{DAFTAR PUSTAKA}

[1] Environmental Bamboo Foundation, 1994. Petunjuk Kerja Pengawetan dengan Sistem Boucherie. Jawa Barat: Yayasan Bambu Lingkungan Lestari.

[2] INBAR, and Government of Mizoram, 2001. Affordable Bamboo Housing in Earthquake

[3] India: BMTPC. Building Materials and Technology Promotion Council (BMTPC). Bamboo: a material for cost effective and disaster resistant housing. 
New Delhi: Ministry of Urban Development \& Poverty Alleviation.

[4] Jansen, Jules, 2007. Building With Bamboo: A Handbook. Warwickshire: ITDG. Stulz, Roland, and Kiran Mukerji, 1993. Appropriate Building Materials: A Catalog of Potential Solutions. Switzerland: SKAT Publication.

[5] Sikumbang, H. (n.d.) Bambu untuk Mengahadapi Pemanasan Global. Bambu untuk Menghadapi Pemanasan Global.

[6] Tsing, Anna Louwenhaupt, 2005. Friction: An Ethnography of Global Connection. Princeton and Oxford: Princeton University Press. 